\title{
Improved "Origami Bird" Protocol Enhances Japanese Students' Understanding of Evolution by Natural Selection: a Novel Approach Linking DNA Alteration to Phenotype Change
}

\author{
Takahiro Yamanoi • Kazuomi Suzuki • \\ Masaharu Takemura • Osamu Sakura
}

Published online: 11 March 2012

(C) Springer Science+Business Media, LLC 2012

\section{Introduction}

Many studies of evolution education have attempted to develop teaching materials on natural selection because of its importance in the evolutionary process (Lauer 2000; Heim 2002; Catley 2006; Kalinowski et al. 2006; Christensen-Dalsgaard and Kanneworff 2008; Frey et al. 2010). However, to our knowledge, no teaching material effectively connects DNA sequencing to the process of natural selection, although current evolutionary biology is closely linked to molecular biology. Current educational

\footnotetext{
T. Yamanoi

Hakuoh Ashikaga Senior High School,

Tadaki-cho1067,

Ashikaga, Tochigi 329-4214, Japan

K. Suzuki $\cdot$ M. Takemura

Graduate School of Mathematics and Science Education,

Tokyo University of Science (RIKADAI),

Kagurazaka 1-3,

Shinjuku, Tokyo 162-8601, Japan

O. Sakura

The Interfaculty Initiative in Information Studies,

University of Tokyo,

Hongo 7-3-1,

Bunkyo, Tokyo 113-0033, Japan

T. Yamanoi $(\square)$

Laboratory of Biology Education,

Graduate School of Mathematics and Science Education,

Tokyo University of Science (RIKADAI),

Kagurazaka 1-3,

Shinjuku, Tokyo 162-8601, Japan

e-mail: yamanoit@fc.hakuoh.ac.jp

content must be modernized to advance evolution education (Hills 2007).

Japanese people easily accept evolution as a fact when compared to people in other countries, especially the U.S. (Sakura 1998; Miller et al. 2006). However, there are some problems in evolution education in Japan, such as using textbooks with outdated scientific theories and a lack of teaching material. These textbooks often cite outdated theories (Shimada 1997, 2004; Nakai 2004), offer a shortage of examples of microevolution (Yamanoi 2008), and include an inaccurate definition of mutation (Yamanoi and Sakura 2010). Fewer teaching materials for evolution have been developed in Japan than in the U.S. and the UK and are hardly introduced in Japanese biology textbooks, particularly for evolutionary mechanisms such as natural selection (Sato and Ohshika 2005). Misconceptions about evolution among high school students are also reported in certain studies. Even after studying evolution, many students fail to understand modern evolutionary concepts, such as linking genes to phenotype, and they mistakenly hold Lamarckism and orthogenesis to be the evolutionary mechanisms (Yamanoi 2008; Fukui 2000; Yamanoi 2010). These misconceptions may be derived from inadequate understanding of the random process in the evolutionary mechanism (Garvin-Doxas and Klymkowsky 2008). We believed that if the students regard mutation as random, not a purposely designed process, then they will disregard Lamarckism and orthogenesis since both ideas assume evolution as a progressive, teleologically designed process.

Biology education based on the new Japanese national curriculum framework, the course of study (CS), and its guidelines for secondary school will begin in high schools in 2013. One of the main educational goals in the CS is to relate evolutionary biology to molecular biology (Ministry 
of Education, Culture, Sports, Science and Technology 2009). Therefore, we propose teaching materials linking DNA alteration to phenotype change to achieve this goal of biology education in Japan.

The "origami bird (Avis papyrus)," invented by Westerling (Westerling 1992), is designed to teach the concept of evolution by natural selection. In our study, we altered the "origami bird" protocol by incorporating a molecular mechanism. We verified the effectiveness of this improved protocol for Japanese high school students by comparing their test scores before and after the experiment.

\section{Method}

\section{Original Origami Bird Protocol}

This fictitious organism (Fig. 1) supposedly lives in arid regions of North Africa. Only those birds that can fly the long distances between oases live long enough to breed successfully. Each bird lays a clutch of three eggs. The first egg has no mutations (a clone of the parent), and the other two eggs have mutations that affect the chicks' morphology. The morphological changes often cause changes in the capabilities to fly long distances. In his paper, Yamanoi reported that the design with small front and large back wings or both small wings is most effective for maximized flight distance, whereas that having large front and small back wings or both large wings minimizes flight distance (Yamanoi 2010). The effects of mutation on their phenotype are determined by a coin flip and a dice throw: a coin flip determines which part of the bird's wings is affected by the mutation, and a dice throw determines how the mutation affects the wing. Only the individual with the longest flying distance among the three survives and breeds. In sum, similar to actual organisms, successful evolution in origami

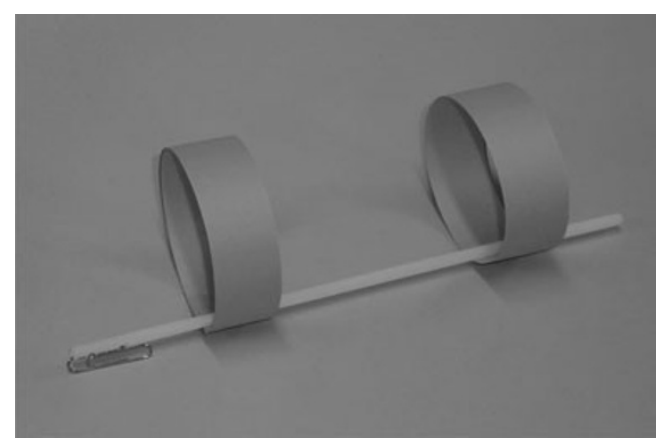

Fig. 1 Origami bird. Westerling (1992) named this fictitious organism "origami bird"; however, Japanese people do not call it "origami" because this word means not balling up but folding the paper. Its construction is simple enough for anyone to replicate: the bird consists of two ringshaped wings made of paper and a straw body (ring-shaped wings' diameter of a parent bird, about $7 \mathrm{~cm}$; straw body length, about $18 \mathrm{~cm}$ ) birds requires genetic variations among individuals by mutation and then environmental selection of the fittest individuals. The original protocol of the origami bird is described in Westerling (1992) and Towle (1999).

We believe that the origami bird has certain advantages for teaching evolution by natural selection: it's enjoyable for students, experimental, easy to create with available materials, allows active learning, follows similar ecology and morphology to those of actual organisms, and provides a simple introduction to the mutation mechanism. No empirical study had been conducted on the effectiveness of "origami bird" instructions on the students' understanding of evolution until Yamanoi $(2008,2010)$.

\section{The Modified Origami Bird Protocol}

Yamanoi $(2008$; 2010) found that the origami bird experiment helped Japanese high school students who studied evolution to improve their understanding in areas such as the timescale of evolution and the non-inevitability of struggle in the process of natural selection. Yamanoi also showed that even after the origami bird experiment, certain misconceptions among students remained, such as those on mutation/speciation, Lamarckism, and orthogenesis. Japanese people probably regard mutation as a large shift such as speciation because the translated Japanese word of mutation "Totsuzen Hen-i" literally means "sudden change." (Yamanoi and Sakura 2010) We found that even after the experiment, the students did not fully understand that the random process of a coin flip and a dice throw means mutation and furthermore that mutation causes random DNA alterations and modification of bird design. As the students did not understand the random process of mutation, they mistakenly thought that birds evolved teleologically (i.e., for the purpose of reaching an oasis).

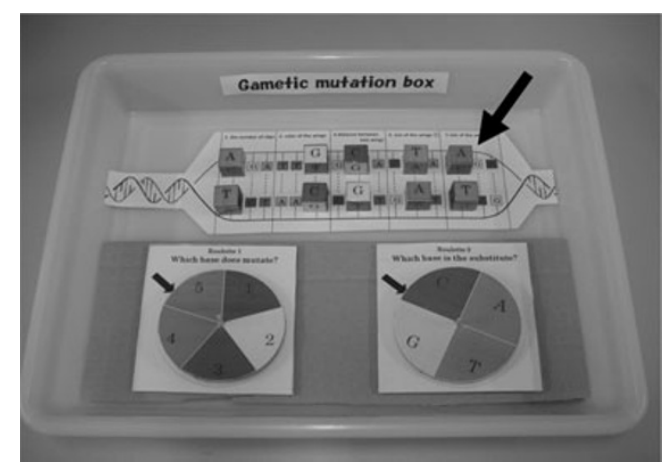

Fig. 2 Gametic mutation box. When the result of roulette in GMB is like this picture, the rotatable fifth base (see arrow in this figure) of the upper strand of DNA will change $A$ to $C$. By reference to the mutation table (Fig. 3), this DNA change will cause the shift of "size of the wings": the front wing will be smaller and the back wing will be bigger 
Mutation Table

(effects of mutation on phenotype)

\section{1. the number of clips}
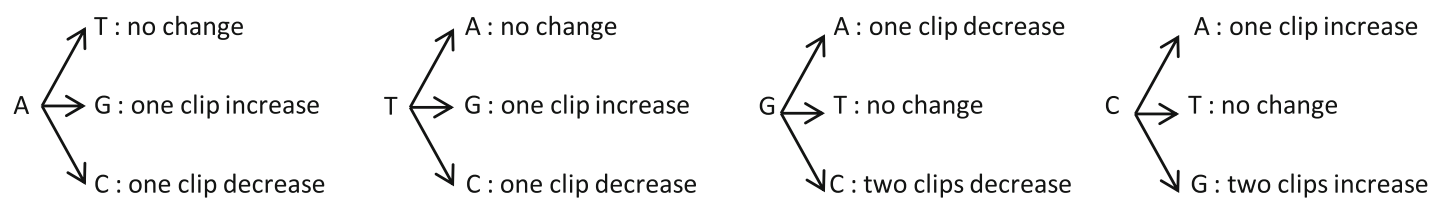

\section{2. color of the wings}
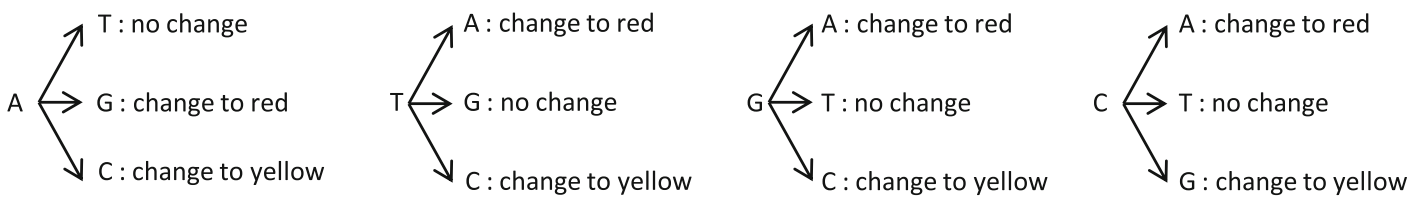

\section{3. distance between two wings}

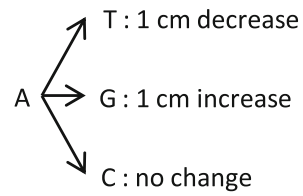

4. size of the wings

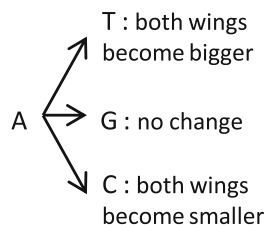

5.size of the wings
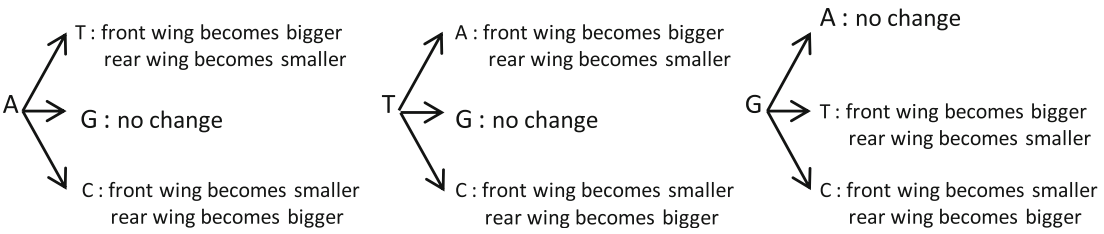

("bigger" means width increase by $1 \mathrm{~cm}$ and length by $2 \mathrm{~cm}$ )

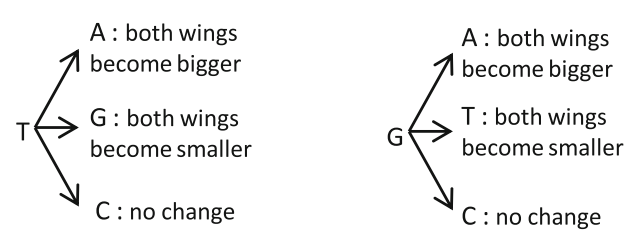

Fig. 3 Mutation table. After spinning the wheels of GMB (Fig. 2), students determine the effect of single base change on bird phenotype by reference to this table

In this study, the improved protocol described in the following text was developed to correct these misconceptions.

Gametic Mutation Box In the original protocol (Westerling 1992), phenotypic changes by mutation occur on the basis of coin flip and dice throw. Results of the origami bird experiment using the original protocol (Yamanoi 2008, 2010) revealed that not all Japanese students understood that the phenotypic changes caused by this process were due to DNA alteration. Therefore, we invented the gametic
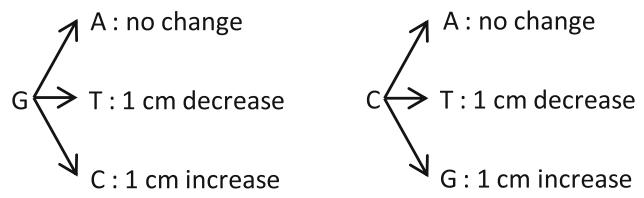

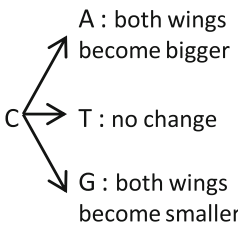
become smaller

mutation box (GMB) to link DNA alteration by mutation to phenotype change. The GMB (Fig. 2) holds two roulette wheels: the left one determines the base that mutates and the right one determines the substitute base. After the DNA alteration, the students checked the type of phenotype change by mutation (here this means only base substitution) based on the "mutation table" (Fig. 3). The magnitude of the phenotype change by mutation in this table was determined by reference to the flight simulation experiment (Yamanoi 2010). In this experiment, each group of six students made 

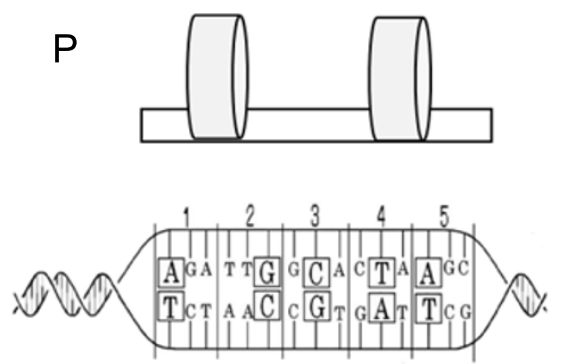

\begin{tabular}{|c|lr|c|c|}
\hline front wing & width & $2 \mathrm{~cm}$ & length & $20 \mathrm{~cm}$ \\
\hline rear wing & width & $2 \mathrm{~cm}$ & length & $20 \mathrm{~cm}$ \\
\hline color of the wings & blue & \\
\cline { 1 - 2 } wing postions & $3 \mathrm{~cm}$ from each edge & \multirow{2}{*}{$\begin{array}{c}\text { maximum } \\
\text { flight } \\
\text { distance }\end{array}$} & $\mathrm{cm}$ \\
\cline { 1 - 2 } $\begin{array}{l}\text { the number of } \\
\text { clips }\end{array}$ & 1 & & & \\
\hline
\end{tabular}

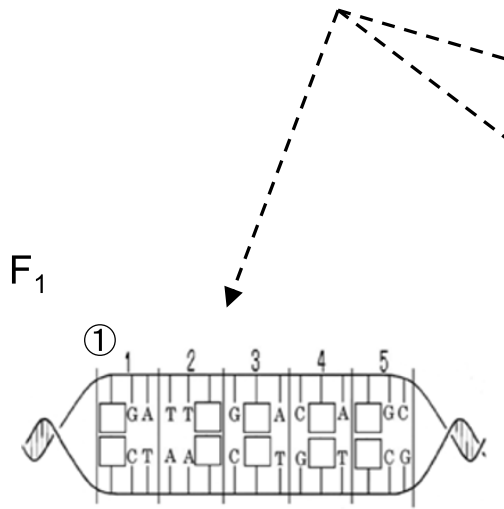

\begin{tabular}{|l|ll|l|l|}
\hline front wing & width $\quad \mathrm{cm}$ & length $\quad \mathrm{cm}$ \\
\hline rear wing & width $\mathrm{cm}$ & length $\mathrm{cm}$ \\
\hline $\begin{array}{l}\text { color of the } \\
\text { wings }\end{array}$ & & $\begin{array}{r}\mathrm{cm} \text { from } \\
\text { each edge }\end{array}$ & $\begin{array}{l}\text { max } \\
\text { flight } \\
\text { distance }\end{array}$ & \\
\hline $\begin{array}{l}\text { wing } \\
\text { postions }\end{array}$ & & $\mathrm{cm}$ \\
\hline $\begin{array}{l}\text { the number } \\
\text { of clips }\end{array}$ & & & \\
\hline
\end{tabular}

\begin{tabular}{|c|c|c|c|c|}
\hline front wing & width & $\mathrm{cm}$ & length & $\mathrm{cm}$ \\
\hline rear wing & width & $\mathrm{cm}$ & length & $\mathrm{cm}$ \\
\hline \multicolumn{5}{|l|}{$\begin{array}{l}\text { color of the } \\
\text { wings }\end{array}$} \\
\hline $\begin{array}{l}\text { wing } \\
\text { postions }\end{array}$ & & $\begin{array}{l}\text { from } \\
\text { edge }\end{array}$ & \multirow{2}{*}{$\begin{array}{l}\max \\
\text { flight } \\
\text { distance }\end{array}$} & \\
\hline $\begin{array}{l}\text { the number } \\
\text { of clips }\end{array}$ & & & & $\mathrm{cm}$ \\
\hline
\end{tabular}

\begin{tabular}{|l|ll|l|l|}
\hline front wing & width $\quad \mathrm{cm}$ & length & $\mathrm{cm}$ \\
\hline rear wing & width $\mathrm{cm}$ & length $\mathrm{cm}$ \\
\hline $\begin{array}{l}\text { color of the } \\
\text { wings }\end{array}$ & & $\begin{array}{r}\mathrm{cm} \text { from } \\
\text { each edge }\end{array}$ & $\begin{array}{l}\text { max } \\
\text { flight } \\
\text { distance }\end{array}$ & \\
\hline $\begin{array}{l}\text { wing } \\
\text { postions }\end{array}$ & & $\mathrm{cm}$ \\
\hline $\begin{array}{l}\text { the number } \\
\text { of clips }\end{array}$ & & & \\
\hline
\end{tabular}

Directions

1) put a circle around a DNA of the surviver with a highlight pen

2) change a base pair in "gametic mutation box"

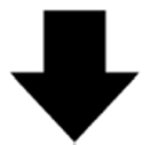

※ Caution

If phenotype of two or three individuals had no change, a bird of the small number survives. to that identical the surviver

(2)

$\mathrm{F}_{2}$ (1)

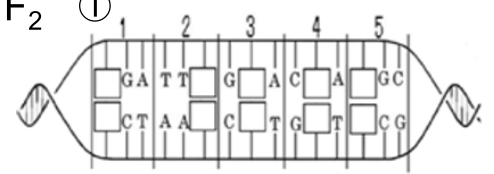

(3)

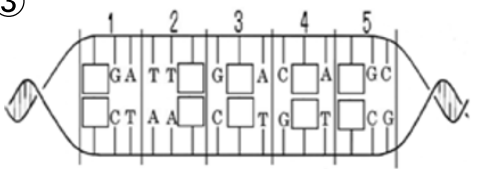

\begin{tabular}{|c|c|c|c|}
\hline front wing & width $\quad \mathrm{cm}$ & length & $\mathrm{cm}$ \\
\hline rear wing & width & length & $\mathrm{cm}$ \\
\hline \multicolumn{4}{|l|}{$\begin{array}{l}\text { color of the } \\
\text { wings }\end{array}$} \\
\hline $\begin{array}{l}\text { wing } \\
\text { postions }\end{array}$ & $\begin{array}{r}\mathrm{cm} \text { from } \\
\text { each edge }\end{array}$ & & \\
\hline $\begin{array}{l}\text { the number } \\
\text { of clips }\end{array}$ & & distance & $\mathrm{cm}$ \\
\hline
\end{tabular}

Fig. 4 Result handout. The students recorded the following three sets of data on their sheet: the change in the DNA sequence after the mutation by GMB, the phenotype change based on the mutation table, and the flight distance of the bird. Also, they encircled the DNA

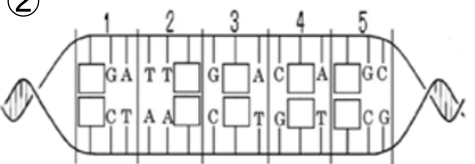

(3)

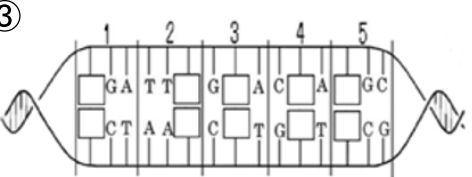

\begin{tabular}{|l|ll|l|l|}
\hline front wing & width $\quad \mathrm{cm}$ & length & $\mathrm{cm}$ \\
\hline rear wing & width $\mathrm{cm}$ & length $\mathrm{cm}$ \\
\hline $\begin{array}{l}\text { color of the } \\
\text { wings }\end{array}$ & & $\begin{array}{r}\mathrm{cm} \text { from } \\
\text { each edge }\end{array}$ & $\begin{array}{l}\text { max } \\
\text { flight } \\
\text { distance }\end{array}$ & \\
\hline $\begin{array}{l}\text { wing } \\
\text { postions }\end{array}$ & & $\mathrm{cm}$ \\
\hline $\begin{array}{l}\text { the number } \\
\text { of clips }\end{array}$ & & & \\
\hline
\end{tabular}

\begin{tabular}{|l|ll|l|l|}
\hline front wing & width $\quad \mathrm{cm}$ & length $\quad \mathrm{cm}$ \\
\hline rear wing & width $\mathrm{cm}$ & length $\quad \mathrm{cm}$ \\
\hline $\begin{array}{l}\text { color of the } \\
\text { wings }\end{array}$ & & $\begin{array}{r}\text { cm from } \\
\text { each edge }\end{array}$ & $\begin{array}{l}\text { max } \\
\text { flight } \\
\text { distance }\end{array}$ & \\
\hline $\begin{array}{l}\text { wing } \\
\text { postions }\end{array}$ & & $\mathrm{cm}$ \\
\hline $\begin{array}{l}\text { the number } \\
\text { of clips }\end{array}$ & & & & \\
\hline
\end{tabular}

sequence of the bird with the longest flight distance among three birds in the generation with a marking pen. In the next generation, mutation will occur for the encircled DNA sequence 
16 different birds with varied wing sizes (small front wing and large back wing, large front wing and small back wing, small front wing and small back wing, large front wing and large back wing) and varied wing positions (one to four centimeters from each edge) (Yamanoi 2010). Then, they threw their birds and measured their flight distances. Each bird was thrown three times, and the average flight distance of each shape was calculated. We created the mutation table design to cause a larger shift of flight distance by a single mutation than in the original protocol. It is known that many mutations are neutral, or nearly so, having very slight effects on fitness (Futuyma 1998), and therefore these changes of birds' morphology and flight distance through a single base substitution were larger than those in an actual organism. However, we considered that the greater change was efficient for teaching the effect of molecular changes on phenotypic changes.

Result Handout The result handout (Towle 1999) was modified to clarify the relationship between DNA alteration by mutation and phenotype change and to show that evolution means changes beyond generations (Fig. 4). The students recorded the following three sets of data on their sheet: the change in the DNA sequence after the mutation by GMB, the phenotype change based on the mutation table, and the flight distance of the bird.

Discussion Handout After the experiment, the students discussed the results within their groups of two to four students. The following three questions were included in the discussion handout:
1. Explain the mechanism of microevolution in the origami bird using the five terms: DNA, mutation, variation of traits, survival rate, and natural selection.

2. The origami bird evolved via natural selection, but not via Lamarckism and orthogenesis. How can you affirm this?

3. How did your understanding of "evolution," "natural selection," and "mutation" change after the experiment? Furthermore, write your impressions of the experiment.

Addition of Neutral Variation and Deletion of Clone Offspring In the original protocol (Westerling 1992), mutation always caused a phenotype change, whereas in our new protocol it does not (see Fig. 3). Furthermore, mutation occurs for all offspring in the new protocol, not for two thirds of them as in the original method, because in an actual organism it is believed that gamete formation necessarily accompanies mutational changes in DNA (Futuyma 1998).

Visual Illustration of the Three Assumptions of Evolution by Natural Selection (Variations of Traits in a Population, Differences of Fitness Depending on the Traits Variation, Inheritance of the Traits) These assumptions are necessary for evolution by natural selection (Futuyma 1998). Yamanoi (2008) reported that even after the origami bird experiment with the original protocol, Japanese high school students who had studied evolutionary concepts failed to understand the three assumptions of evolution by natural selection. We dealt out to the students our handout with a visual illustration to confirm that the origami bird experiment applies the three assumptions (Fig. 5).

1. Variations of traits in a population

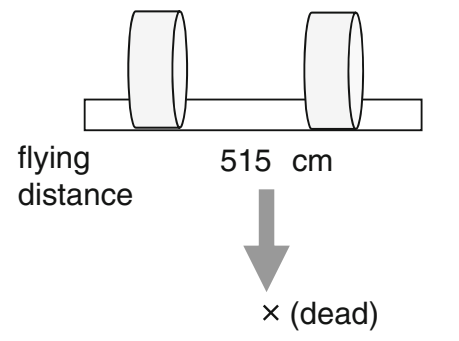

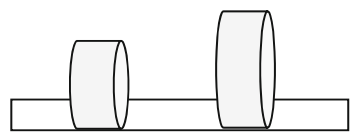

$723 \mathrm{~cm}$

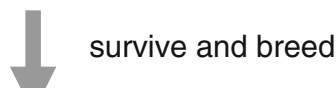

$\times($ dead $)$

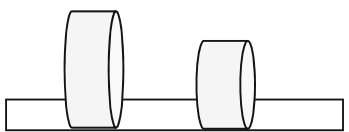

$333 \mathrm{~cm}$

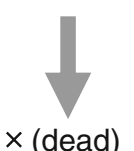

$\times($ dead $)$

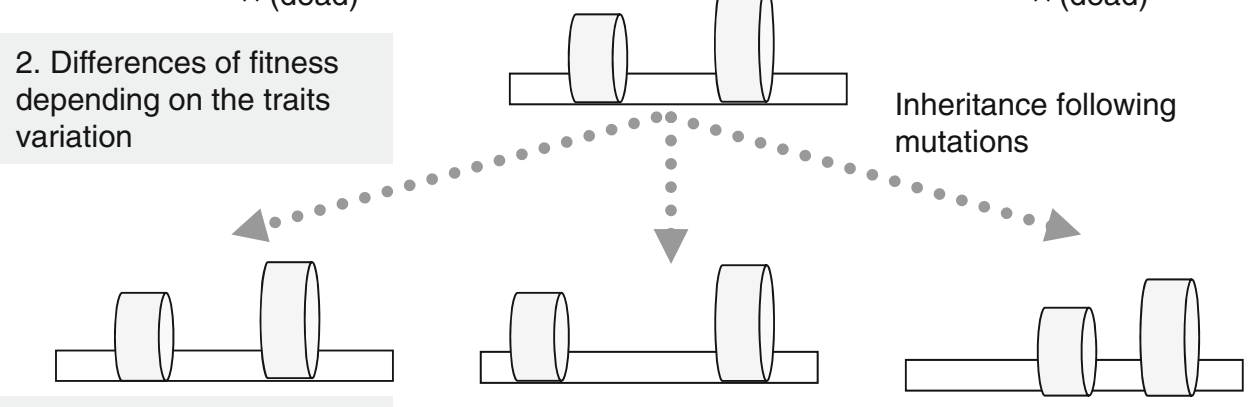

3. Inheritance of the traits

Fig. 5 Visual illustration of the three assumptions of evolution by natural selection 
Attachment of a Clip to the Bird's Tip One clip was attached to the tip of a straw to stabilize the flights of the birds (Fig. 1). The number of clips attached to the bird's tip is changed by mutation following the mutation table (Fig. 3).

Setting of Oasis A tub (diameter, about 90 centimeters; depth, about 15 centimeters) representing an oasis was set in the flying field at a ten-meter point from the place where birds were thrown into flight. We hypothesized that the students' motivation with the experiment remained high because of the simulated oasis. The oasis was set only for keeping up their motivation for the experiment. Fitness of origami birds depends on their flight distance, so whether they land on the oasis does not affect the fitness of origami birds.

\section{Student Experiment and Pre-/Post-tests}

We conducted the student experiment in a Japanese high school in 2009. The students $(N=67$, male/female $=19: 48)$ were biology majors and had completed studying evolutionary concepts (e.g., natural selection, mutation, microevolution, macroevolution, and biological species). It took two class sessions ( 45 minutes $\times$ two) to complete the process: in the first session, we performed the origami bird experiment with the new protocol, and in the next session, we held the
Fig. $6 \mathrm{~T} / \mathrm{F}$ test about evolutionary concepts. Answers of the test questions were not written on the distributed papers for students. "T" means "true," "F" means "false"
[Definition of evolution]

1) Evolution is the change of an organism from simple to complex. (F)

2) Evolution is the change of an organism from lower to higher form. (F)

3) Evolution is indicated by the changing proportion of individuals with discrete genotypes in population beyond generations. ( $T$ )

4) Evolution is indicated by the changing proportion of individuals with discrete traits in a population in response to environmental changes during a single generation. $(F)$

5) Evolution is indicated by the changing proportion of individuals with discrete traits in a population toward one's purposes. ( $F$ )

6) Evolution is indicated by the changing proportion of individuals with discrete traits in a population beyond generations. $(\mathrm{T})$

7) Evolution is indicated by population changes toward a particular course determined by the species with no relation to the environment. $(F)$

8) If the generation time of an organism is short, then we can observe evolutionary changes in that organism during a few months. (T)

9) Evolutionary changes require over ten thousand years regardless of the generation time of the species. (F)

10) If organisms frequently use a particular organ for a lifetime, then the gene related to the organ undergoes changes. In the next generation, the organ will develop through evolutionary change. (F)

11) Only speciation is called evolution. $(F)$

12) The blind gut and coccyx in humans have lost their functions. These changes are examples of evolution. (T)

[Natural selection]

1) The process of natural selection definitely involves struggle within species. $(F)$

2) The process of natural selection definitely involves struggle between species. (F)

3) Natural selection requires intraspecific variation of variability and/or reproductive rate in the environment. (T)

4) If natural selection occurs, then only the winners of the struggle survive. $(F)$

5) Natural selection randomly causes individuals to survive and reproduce or die. (F)

6) The direction of natural selection depends on the environment. (T)

7) Once natural selection favored neck elongation; this change definitely continues beyond a generation. (F)

8) Similar to natural selection, human beings can cause species to promote evolutionary change. (T)

9) If different natural selection occurs between sexes, then different evolution will arise between sexes. (T)

The assumptions of natural selection

Select one appropriate (just appropriate enough) sentence as the assumption of natural selection.

( ) 1 There is variation of traits within species.

( ) 2 There is variation of traits within species. Variation of traits is inheritable.

( $T$ ) 3 There is variation of traits within species. Variation of traits is inheritable. Differences in traits cause variation of the number of offsprings.

( ) 4 There is variation of traits within species. Variation of traits is inheritable. Differences in traits cause variation of the number of offsprings. Only Intelligent individuals survive and all unintelligent individuals die.

[Mutation]

1) Mutation of gametes definitely has a negative effect on the variability of the offspring. (F)

2) Mutation of gametes definitely has a positive effect on the variability of the offspring. (F)

3) Mutation hardly occurs naturally. (F)

4) The gene that mutates is determined preliminarily. $(F)$

5) Mutation always causes speciation. ( $F$ )

6) DNA mutation does not necessarily cause change of phenotype. (T) 
discussion with the discussion handouts. We conducted the tests to compare the students' understanding of evolution before and after the experiment (Fig. 6). These pre-/posttests were identical, developed in reference to the sources cited in many papers about evolution education (Fukui 2000; Brumby 1984; Bishop and Anderson 1990; Fukui and Tsuruoka 2002; Fuyama 2004; Hasegawa 2004). There were a total of 28 questions concerning "definition of evolution," "natural selection," and "mutation" in the test. We statistically compared the scores before and after the experiment (including discussion) using the paired $t$-test, Wilcoxon signed ranks test, and chi-square analysis (Sysstat 8.0) (Yamanoi and Miyashita 2005).

\section{Results}

\section{Comparison of Pre-/Post-tests}

Total test scores (the number of correct answers over a total of 28 questions) increased after the experiment and discussion (pre-test average score $=0.67$, post-test average score $=0.74$; $d f=66, t=-5.421, p=0.0001$ ), with five students achieving an approximately $30 \%$ higher score in the post-test than in the pre-test (Fig. 7). We performed further statistical analysis to verify the effect of test scores before the experiment. The students were divided into two groups based on the average score of the pre-test: higher $(>0.67)$ and lower $(<0.67)$ scores. The scores increased significantly in both groups after the experiment/discussion (higher: $n=34, z=2.382, p=0.017$; lower: $n=33, z=3.842, p=0.0001)$. The chi-square test revealed that accuracy rates in six questions increased after the experiment/discussion (Fig. 8a-c; Table 1), which include three questions relating to the rejection of teleological thought ("Definition of Evolution" \#1, \#2, and \#5) and one question

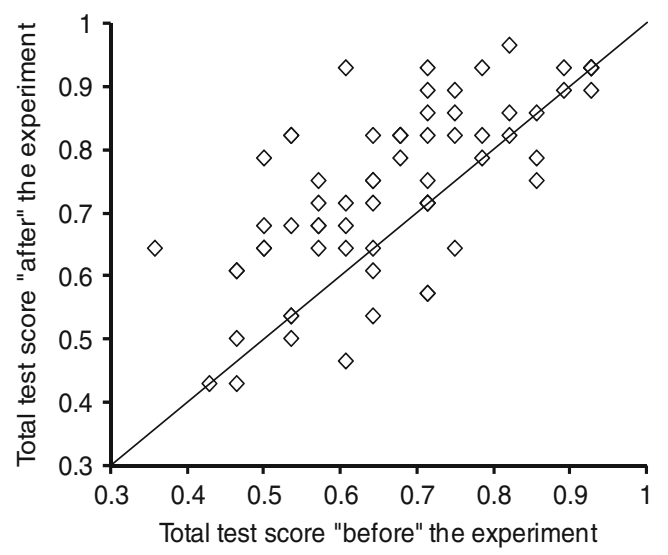

Fig. 7 Comparison of total test score before and after the experiment. Values mean accuracy rate (over a total of 28 questions). The straight line indicates $y=x$; plots above this line indicate an increase in the scores after the experiment a) Definition of evolution

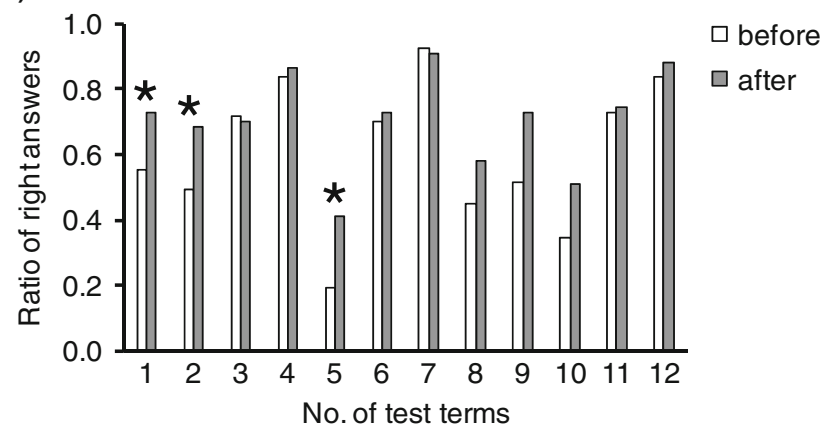

b) Natural selection

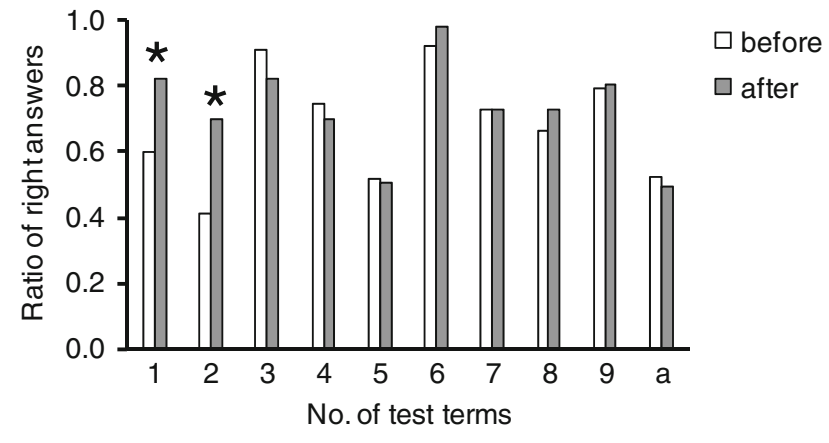

c) Mutation

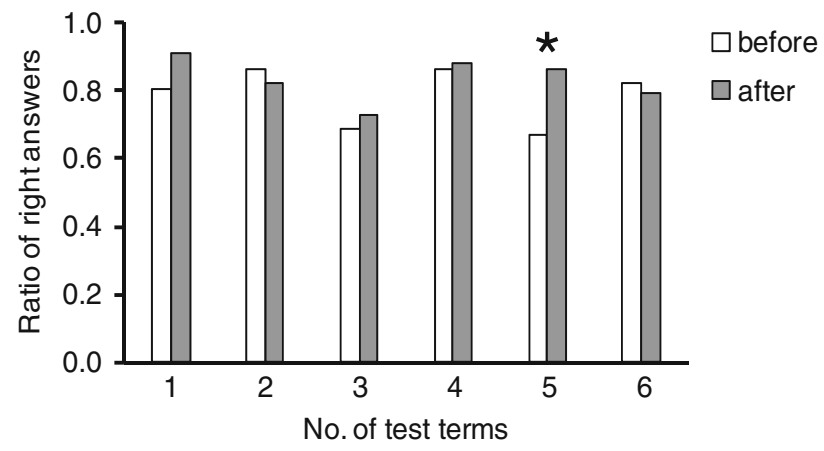

Fig. 8 a-c Changes of average right answer ratio of individual questions before and after the experiment. Asterisks indicate significant difference at 0.05 level

on mutation/speciation misconception ("Mutation" \#5). However, the ratio of right answer did not decrease on any questions (Fig. 8a-c; Table 1). Figure 9 shows that most students thought that this experiment was enjoyable and useful for their understanding of the concept of evolution.

Students' Impression Inferred from Descriptions of Discussion Handout

Details of positive impressions reported by more than three students after the experiment were as follows: gained further understanding of evolution by natural selection $(n=14)$, enjoyable $(n=14)$, wanted to make birds that can fly to the 
Table 1 Changes of average right answer ratio of individual questions assessed by $\chi^{2}$ test

\begin{tabular}{|c|c|c|c|}
\hline & No. of test terms & $\chi^{2}$ & $p$ \\
\hline \multirow[t]{12}{*}{ Definition of evolution } & 1 & 4.67 & 0.03 \\
\hline & 2 & 5.21 & 0.02 \\
\hline & 3 & 0.04 & 0.85 \\
\hline & 4 & 0.23 & 0.63 \\
\hline & 5 & 6.98 & 0.008 \\
\hline & 6 & 0.15 & 0.70 \\
\hline & 7 & 0.01 & 0.75 \\
\hline & 8 & 2.42 & 0.12 \\
\hline & 9 & 7.12 & 0.008 \\
\hline & 10 & 3.69 & 0.06 \\
\hline & 11 & 0.04 & 0.84 \\
\hline & 12 & 0.55 & 0.46 \\
\hline \multirow[t]{10}{*}{ Natural selection } & 1 & 8.14 & 0.004 \\
\hline & 2 & 8.66 & 0.003 \\
\hline & 3 & 1.53 & 0.22 \\
\hline & 4 & 0.34 & 0.56 \\
\hline & 5 & 0 & 1 \\
\hline & 6 & 1.36 & 0.24 \\
\hline & 7 & 0 & 1 \\
\hline & 8 & 0.88 & 0.35 \\
\hline & 9 & 0.05 & 0.83 \\
\hline & Assumptions & 0.12 & 0.73 \\
\hline \multirow[t]{6}{*}{ Mutation } & 1 & 3.01 & 0.08 \\
\hline & 2 & 0.51 & 0.48 \\
\hline & 3 & 0.33 & 0.57 \\
\hline & 4 & 0.07 & 0.79 \\
\hline & 5 & 7.10 & 0.008 \\
\hline & 6 & 0.19 & 0.66 \\
\hline
\end{tabular}

oasis $(n=10)$, became more interested in evolution $(n=8)$, gained further understanding about blindness of mutation and evolution $(n=5)$, learned about surprising effects of phenotype changes on flight distance $(n=5)$, wanted to conduct the experiment again $(n=5)$, and learned that mutation causes positive, negative, and neutral effects on phenotype $(n=4)$. Conversely, the negative impression $(n>3)$ included just one point: needed more time to conduct the experiments $(n=4)$.

\section{Discussion}

The origami bird with the improved protocol enhanced these Japanese high school students' understanding of evolutionary concepts. This was indicated by their total test scores after the experiment/discussion that increased regardless of their pre-test scores. Furthermore, judging from the students' impressions, a) Was the experiment enjoyable?

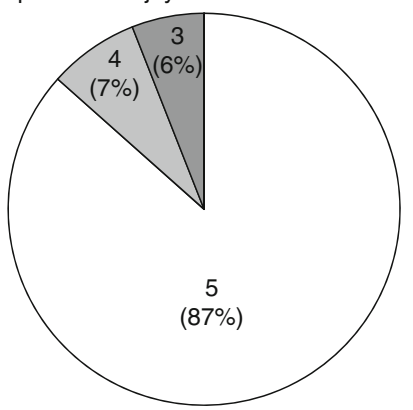

b) Was the experiment useful for understanding evolution?

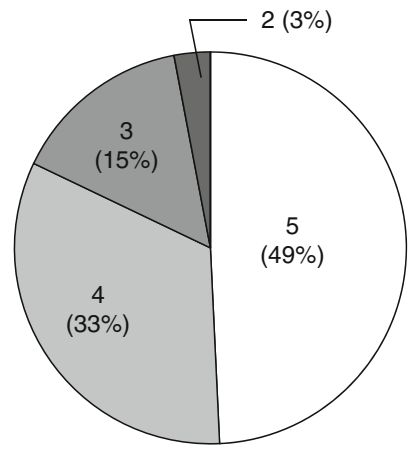

Fig. 9 a, b Students' impressions. After the experiment, the students rated their impressions on a scale of one of five (positive $=5$ and negative $=1$ )

the new protocol had no influence in decreasing their motivation to perform the experiment.

Similar to my previous results with Westerling's (Yamanoi 2008, 2010) original protocol, the students improved their understanding about the timescale of evolution ("Definition of evolution" \#9) and the non-inevitability of struggle in the process of natural selection ("Natural selection" \#1 and \# 2). Furthermore, they improved their understanding of mutation and rejected the notion of Lamarckism and orthogenesis. These improvements and rejections had not occurred in my previous research (Yamanoi 2010). So we conclude that our modifications of the original protocol in this study led to these improved

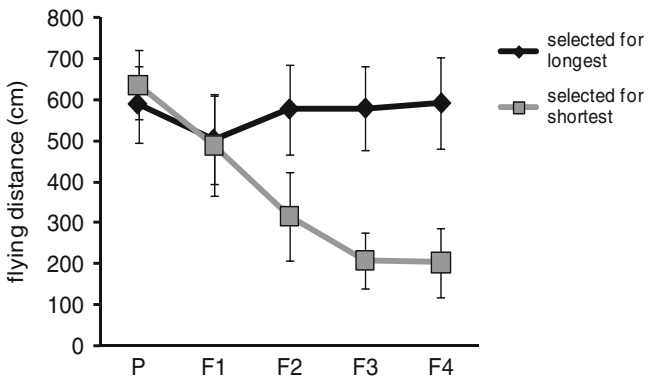

Fig. 10 A preliminary students' experiment introducing different directions of natural selection. Twenty-four groups (two or three students a group) were divided into two. Error bars indicate standard deviation 
understandings. Through the experiment and the following discussion, the students probably came to regard mutation correctly as random DNA alteration, not speciation, and then understood evolution by linking changes on the DNA level to those on the phenotype level and rejected teleological concepts. We also suggest that this improved protocol has the potential to be effective for not only Japanese high school students but also high school and undergraduate students in other countries because many previous studies have revealed that these students also hold outdated evolutionary concepts similar to Lamarckism and orthogenesis (Bardapurkar 2008). As is known, teaching materials effective for rejection of teleology are scarce in other countries as well, and hence our research may be an important first step toward filling that gap.

Our improvement of Westerling's original protocol yielded significant elevation of the students' understanding of evolution, but the change was slight (average score shift was 0.67 to 0.74). Therefore, we considered further modification of our protocol as follows. The students were divided into two groups with relation to the direction of natural selection. In one group, a bird with the longest flying distance was selected. In the others, a bird with the shortest flying distance was selected. We preliminarily conducted student experiments with this new protocol, with two birds' populations showing different evolutionary trajectories over four generations (Fig. 10). This modification is considered to enhance understanding of the variability in the direction of natural selection: selection does not always favor the long flight, which will lead to the rejection of teleological thoughts. We expect that further verifications and improvement of our protocol will be performed in many countries.

Acknowledgements We thank all members of Sakura and Takemura laboratories for their useful comments. This study was partially supported by Grants-in-Aid for Scientific Research (B) \#22330253 (M. T.) and Scientific Research (B) \#21300321 (O. S.) from the Ministry of Education, Culture, Sports, Science, and Technology of Japan.

\section{References}

Bardapurkar A. Do students see the "selection" in organic evolution? A critical review of the causal structure of student explanations. Evol Educ Outreach. 2008;1:299-305.

Bishop BA, Anderson CW. Student conceptions of natural selection and its role in evolution. J Res Sci Teach. 1990;27:415-27.

Brumby MN. Misconceptions about the concept of natural selection by medical biology students. Sci Educ. 1984;68:493-503.

Catley KM. Darwin's missing link - a novel paradigm for evolution education. Sci Educ. 2006;90:767-83.

Christensen-Dalsgaard J, Kanneworff M. Evolution in Lego ${ }^{\circledR}$ : a physical simulation of adaptation by natural selection. Evol Educ Outreach. 2008;2:518-26.

Frey FM, Lively CM, Brodie III ED. Selection and evolution with a deck of cards. Evol Educ Outreach. 2010;3:114-20.
Fukui T. Study on evolutionary concepts of high school students: students' misconceptions of evolution in biology. J J Biol Edu. 2000;40:122-38. in Japanese with English abstract.

Fukui T, Tsuruoka Y. Investigation on children/students' images of evolution: what kind of phenomenon is evolution? Bulletin of the Center for Educational Research and Training, Faculty of Education, Chiba University. 2002;9:35-44 (in Japanese).

Futuyma DJ. Evolutionary biology. 3rd ed. Sunderland, Massachusetts: Sinauer; 1998.

Fuyama Y. Evolution education from a viewpoint of genetics. Iden. 2004;58:67-72. in Japanese.

Garvin-Doxas K, Klymkowsky MW. Understanding randomness and its impact on student learning: lessons learned from building the biology concept inventory (BCI). CBE-Life Sci Edu. 2008;7:227-33.

Hasegawa M. Difficulties in teaching evolution: popularizing the correct understanding of the concept of evolution. Iden. 2004;58:7881. in Japanese.

Heim WG. Natural selection among playing cards. Am Biol Teach. 2002;64:276-8.

Hills DM. Making evolution relevant and exciting to biology students. Evolution. 2007;61:1261-4.

Kalinowski ST, Mark L, Taper ML, Metz AM. Can random mutation mimic design? A guided inquiry laboratory for undergraduate students. Genetics. 2006;174:1073-9.

Lauer TE. Jelly Belly jelly beans and evolutionary principles in the classroom: appealing to the students' stomachs. Am Biol Teach. 2000;62:42-5.

Miller JD, Scott EC, Okamoto S. Public acceptance of evolution. Science. 2006;313:765-6.

Ministry of Education, Culture, Sports, Science and Technology. Course of study for secondary schools in Japan. Printing Bureau, Ministry of Finance, Tokyo. 2009.(in Japanese).

Nakai S. Teaching evolution for elementary school pupils: toward paradigm shift in evolution teaching in secondary education. Iden. 2004;58:56-66. in Japanese.

Sakura O. Similarities and varieties: a sketch on the acceptance of Darwinism and sociobiology in Japan. Biol Philos. 1998;13:341-57.

Sato T, Ohshika K. Analysis of textbooks and teaching materials about teaching unit of evolution in high school biology. Bulletin of the Graduate School of Education, Hiroshima University, Part II.2005;54:17-24 (in Japanese with English abstract).

Shimada M. How to teach evolution in high schools. Kagaku. 1997;67:22-31. in Japanese.

Shimada M. How to teach evolution? An introduction to special issue. Iden. 2004;58:26-34. in Japanese.

Towle A. Modern biology. Texas: Holt, Rinehart and Winston; 1999.

Westerling K. http://www.indiana.edu/ ensiweb/lessons/origami.html. 1992.

Yamanoi T. Analysis of Japanese Biology 2 textbooks and the introduction of a student experiment with origami birds (Avis papyrus) aiming at further understanding of the mechanism of evolution. J J Biol Edu. 2008;48:197-210. in Japanese with English abstract.

Yamanoi T. "Origami bird (Avis papyrus)," a teaching material about evolution by natural selection: ideas of further improvement inferred from student's experiment. Iden. 2010;64:96-103. in Japanese.

Yamanoi T, Miyashita T. Foraging strategy of nocturnal orb-web spiders (Araneae: Neoscona) with special reference to the possibility of beetle specialization by $N$. punctigera. Acta Arachnol. 2005;54:13-9.

Yamanoi T, Sakura O. Analysis of the Japanese high school Biology II textbooks with special reference to the four keywords: evolution, natural selection, mutation, and species. Biol Sci. 2010;62:39-45. in Japanese. 